\title{
Moderating Effects of Parental Feeding Practices and Emotional Eating on Dietary Intake among Overweight African American Adolescents
}

\author{
Mary Quattlebaum ${ }^{1}$, Dawn K. Wilson ${ }^{1, *}$, Allison M. Sweeney ${ }^{2}$ (D) and Nicole Zarrett ${ }^{1}$ \\ 1 Department of Psychology, University of South Carolina, Columbia, SC 29208, USA; \\ mjq@email.sc.edu (M.Q.); zarrettn@mailbox.sc.edu (N.Z.) \\ 2 College of Nursing, University of South Carolina, Columbia, SC 29208, USA; sweeneam@mailbox.sc.edu \\ * Correspondence: wilsondk@mailbox.sc.edu; Tel.: +1-803-777-4137
}

Citation: Quattlebaum, M.; Wilson, D.K.; Sweeney, A.M.; Zarrett, N. Moderating Effects of Parental Feeding Practices and Emotional Eating on Dietary Intake among Overweight African American Adolescents. Nutrients 2021, 13, 1920. https://doi.org/10.3390/nu13061920

Academic Editor: Ekhard E. Ziegler

Received: 11 March 2021

Accepted: 31 May 2021

Published: 3 June 2021

Publisher's Note: MDPI stays neutral with regard to jurisdictional claims in published maps and institutional affiliations.

Copyright: (c) 2021 by the authors. Licensee MDPI, Basel, Switzerland. This article is an open access article distributed under the terms and conditions of the Creative Commons Attribution (CC BY) license (https:// creativecommons.org/licenses/by/ $4.0 /)$.

\begin{abstract}
This study examined the effects of parental feeding practices and adolescent emotional eating (EE) on dietary outcomes among overweight African American adolescents. Based on Family Systems Theory, it was hypothesized that parental feeding practices, such as parental monitoring and responsibility, would buffer the effects of EE on poor dietary quality, whereas practices such as concern about a child's weight, restriction, and pressure-to-eat would exacerbate this relationship. Adolescents $(\mathrm{N}=127$; Mage $=12.83 \pm 1.74 ;$ MBMI $\%=96.61 \pm 4.14)$ provided baseline data from the Families Improving Together (FIT) for Weight Loss trial and an ancillary study. Dietary outcomes (fruit and vegetables (F\&Vs), energy intake, sweetened beverage, total fat, and saturated fat) were assessed using random 24-h dietary recalls. Validated surveys were used to assess adolescentreported $\mathrm{EE}$ and parental feeding practices. Results demonstrated a significant interaction between EE and parental monitoring (adjusted analyses; $B=0.524, S E=0.176, p=0.004)$, restriction $(B=-0.331$, $S E=0.162, p=0.043)$, and concern $(B=-0.602, S E=0.171, p=0.001)$ on F\&V intake; under high monitoring, low restriction, and low concern, EE was positively associated with F\&V intake. There were no significant effects for the other dietary outcomes. These findings indicate that parental feeding practices and EE may be important factors to consider for dietary interventions, specifically for F\&V intake, among overweight African American adolescents.
\end{abstract}

Keywords: parental feeding practices; emotional eating; dietary intake; adolescent; African Americans

\section{Introduction}

The prevalence rate of adolescent obesity in the US is $20.6 \%$ [1], with higher rates of overweight or obesity shown among African American adolescents (40\%) compared to their White peers (31\%) [2]. Adolescent obesity has largely been attributed to physical inactivity, sedentary behaviors, and increased intake of energy-dense foods [3]. Problematic eating behaviors, such as emotional eating - the tendency to overeat in response to negative emotions-may also contribute to adolescent obesity [4]. Specifically, emotional eating has been linked to unhealthy dietary intake, including increased intake of energy-dense foods and sweetened beverages and reduced fruit and vegetable $(\mathrm{F} \& \mathrm{~V})$ intake, among diverse adolescent samples (e.g., African American and Latino) [5-8]. Adolescent African Americans have shown higher rates of emotional eating compared to their White peers, and thus may be at greater risk for potential weight gain [9]. Emotional eating has also been associated with poor psychosocial outcomes (e.g., lower quality of life, mental health concerns, and body dissatisfaction) $[10,11]$, and growing evidence demonstrates an association between adolescent emotional eating and dietary intake and parental feeding practices (parental behaviors to influence their child's food intake or eating behaviors) [12,13]. Thus, further examination of parental feeding practices may elucidate the relationship between emotional eating and poor dietary quality, which may be particularly important to African American adolescents. 
African American adolescents and their families are disproportionately exposed to various social-environmental conditions (e.g., poverty, neighborhood disorder, and lack of access to healthy foods) that may contribute to a greater risk of emotional eating and related health consequences [14-17]. African Americans may cope with these social environmental factors and chronic stress by engaging in emotional eating, which may be due to a lack of resources $[18,19]$. For example, one study showed that having limited access to high-dietary-quality foods in homes and neighborhoods was associated with greater consumption of high-fat, high-sugar foods within an adolescent sample (90.7\% African American) [14]. Thus, African American adolescents who experience emotional eating may be at risk of consuming more poor-dietary-quality foods readily available in their home and neighborhood environment. In addition, parental modeling may impact adolescents' eating patterns. In the context of the family system, parents may model poor eating habits, such as emotional eating in response to stress [20]. Thus, understanding parenting moderators of emotional eating on dietary outcomes may be particularly important among high-risk overweight African American adolescents.

Family Systems Theory (FST) proposes that supportive, nurturing family interactions and positive parenting behaviors (warmth and communication) are important for promoting healthy development in adolescence, such as nutritious eating habits [21,22]. Parenting styles, including authoritative (high responsiveness and high demandingness) and authoritarian (low responsiveness and high demandingness), have shown important associations with adolescents' eating behaviors and dietary intake [23]. Specifically, authoritative practices have been linked to higher F\&V intake in children and adolescents [24], whereas authoritarian practices have been related to lower F\&V intake [25]. In line with FST, parental feeding practices, such as monitoring a child's eating (tracking a child's eating) and responsibility (perception of parental responsibility for child's eating), have been associated with reduced sweetened beverage intake and less emotional eating in children and adolescents $[26,27]$. In contrast, more restrictive parental feeding practices, including restricting a child's access to foods, concern about a child's weight, and pressure-to-eat have been linked to high-fat, high-sugar intake and high rates of emotional eating [28,29]. Based on FST, parental feeding practices, such as monitoring and responsibility, may help facilitate a supportive home climate, which may buffer the negative effects of adolescent emotional eating on dietary outcomes [30].

Few previous studies have examined parenting factors (parenting styles and feeding practices) in relation to adolescent dietary intake among solely African American families, and of the studies to date, there have been inconsistent results. Specifically, some research has shown that restrictive parental feeding practices have been related to greater $\mathrm{F} \& \mathrm{~V}$ intake among low-income, predominantly African American children (43\% African American) [31]. Furthermore, prior studies have shown that more demanding parenting practices (e.g., restriction and pressure-to-eat) were associated with increased self-regulation among African American adolescents, particularly among low-income families [32,33]. Conversely, other studies have shown that authoritative parental feeding practices are related to higher dietary quality among low-income minority children and adolescents ( $38 \%$ African American sample) [34]. More recent investigations by our group that included a sample of African American adolescents demonstrated that parental responsiveness was associated with high dietary self-efficacy for eating healthy [35]. Furthermore, another analysis showed that for African American adolescents who perceived higher parental pressure-to-eat, parental stress was associated with higher adolescent body mass index (BMI) [36]. The current study expands on past research by examining the moderation effects of parental feeding practices (both responsiveness and restrictive parenting practices) and adolescents' emotional eating on dietary outcomes among high-risk, overweight African American adolescents.

Few studies have examined the moderating effects of parental feeding practices and emotional eating on dietary outcomes among African American adolescents; however, studies on adolescents in general show the relevance of this research. A recent study examined the moderating role of parental feeding practices and adolescent reward sen- 
sitivity on dietary intake (sugar-sweetened beverages and snack foods (categorized as healthy or unhealthy)) among Flemish adolescents [37]. Reward sensitivity is recognized as an individual's responsiveness to reward cues [38] and has been associated with greater emotional eating, poor dietary habits, and risk for overweight [39-41]. Van Lippevelde et al. [37] found that with greater restriction and pressure-to-eat, for adolescents with high (vs. low) reward sensitivity there was a positive association with high-fat, high-sugar snack intake (e.g., cookies, pastries, fries, etc.). Thus, parental feeding practices, such as restriction and pressure-to-eat, exacerbated consumption of sugar and fat intake among adolescents with high reward sensitivity. This prior study did not include an ethnically diverse adolescent sample, and thus the present study examined the moderating effects of parental restriction and pressure-to-eat on emotional eating in predicting African American adolescents' dietary intake.

Several other studies on inhibition and loss of control (LOC) eating also provide relevant information on moderated effects similar to those proposed in our study. For example, one study examined the interactive effects of parental feeding practices and preadolescent impulsivity (i.e., deficits in inhibition or control) on emotional eating among predominantly White preadolescents [42]. Farrow [42] found that under low or average, but not high, levels of parental monitoring of a child's eating, preadolescent impulsivity was positively associated with emotional eating. Additional studies have examined the role of parental feeding practices in relation to child and adolescent LOC eating, which is recognized as a feeling of loss of control while eating, regardless of the amount of food consumed [43]. LOC eating is often paired with negative emotions and increased intake of energy-dense foods and has been shown to coincide with emotional eating behaviors, particularly among overweight youth [44-47]. Given the parallels between emotional eating and LOC eating, including negative affect, risk for poor-dietary-quality intake, and weight gain, this construct may be particularly relevant to the present study. A recent study assessed the interactive effects of parental feeding practices and adolescent weight status on LOC eating among adolescents [48]. The study findings indicated that for high maternal restriction of adolescent's eating, weight status was positively associated with LOC eating. Thus, the impacts of restrictive parental feeding practices on LOC eating may be particularly exacerbated among adolescents with overweight or obesity. In sum, these studies highlight the important moderating role of parental feeding practices on problematic eating behaviors tied to negative emotions, particularly among high-risk adolescents. This research is limited, however, in that few past studies have examined these relationships among overweight African American adolescents.

The purpose of the current study was to examine the moderating effects of parental feeding practices on adolescent emotional eating in predicting dietary outcomes $(\mathrm{F} \& \mathrm{~V}$, energy intake, sweetened beverage, total fat, and saturated fat) among overweight African American adolescents in the Families Improving Together (FIT) for Weight Loss Trial $[49,50]$. Based on FST and previous research [37,42], it was hypothesized that parental feeding practices, including monitoring a child's eating and perceived parental responsibility, would buffer the association between adolescent emotional eating and poor dietary intake, such that higher-dietary-quality outcomes were more likely (higher F\&V intake, lower energy intake, sweetened beverage, total fat, and saturated fat). Conversely, it was hypothesized that parental feeding practices, such as restriction of a child's eating, concern about a child's weight, and parental pressure-to-eat, would exacerbate the association between adolescent emotional eating and dietary intake, such that lower-dietary-quality outcomes were more likely (lower F\&V, higher energy intake, sweetened beverage, total fat, and saturated fat).

\section{Materials and Methods}

\subsection{Participants}

The current study included 127 African American parent-adolescent dyads from the FIT Weight Loss trial $[49,50]$. The participants also took part in an ancillary study, the Understanding Heredity and the Environment in African American Risk of Hypertension 
(HEART) study [51], which assessed stress and emotional eating in adolescents. Adolescents were eligible for participation if they (1) identified as African American, (2) were overweight or obese (BMI $\geq 85$ th percentile), (3) were between 11-16 years old, (4) had internet access, and (5) had a parent or guardian willing to participate in the study. Adolescents were excluded from the study if they had a medical or psychiatric condition that might interfere with physical activity or dietary habits, were taking any medications that could impact their weight or appetite, or if they were currently enrolled in another structured weight-loss program. Participants residing in Columbia, SC, were recruited through local clinics, schools, and community centers (i.e., churches and recreational centers) [52].

\subsection{Procedures}

The purpose of the FIT trial was to evaluate the efficacy of a motivational plus familybased weight-loss intervention versus a comprehensive health education program on reducing BMI in overweight and obese African American adolescents and their caregivers [49] (ClinicalTrials.gov ID\#: NCT01796067). Baseline assessments were completed over a 2-week orientation period before starting the intervention. All FIT participants were also invited to complete the HEART study to further understand participants' stress measures, including emotional eating. On average, participants completed FIT and HEART baseline visits within approximately two months of each other. The current study only evaluated the baseline data from both the FIT trial and HEART study. The FIT trial did not target emotional eating behaviors, and thus we do not expect there to be significant differences in emotional eating responses among the participants that completed their baseline visit at pre-intervention versus during the intervention. Moreover, prior studies utilizing data from the FIT trial and HEART study did not show significant effects when examining treatment effects in relation to time of measurement for a variable that was collected in the HEART study [36]. Adolescents and their parents provided written informed assent and consent, respectively, prior to participation in the study. Both studies were approved by the University of South Carolina Institutional Review Board. After completing study procedures, participants were compensated with $\$ 20$ for their baseline assessment visit. Additional details regarding study design and procedures for the FIT trial are available [49].

\subsection{Measures}

\subsubsection{Demographic Information}

Demographics were collected on adolescent age, adolescent sex, parent education, annual household income, parent marital status, and number of children under 18 years old living at home.

\subsubsection{Anthropometrics}

Adolescent and parent height and weight were measured by a trained research assistant with a Shorr height board and SECA 880 digital scale, respectively. Height was measured in centimeters and weight was measured in kilograms. Two measurements of height and weight were collected, and a third measurement was taken if there was a difference greater than $1.0 \mathrm{~cm}$ or $0.5 \mathrm{~kg}$ between the first two measurements. BMI was calculated with an average of the height and weight measurements based on the Center for Disease Control (CDC) for adolescents and adults, respectively. Parent BMI values were used as a covariate in the current study.

\subsubsection{Emotional Eating}

Emotional eating was assessed with the Three-Factor Eating Questionnaire-Revised 18-item (TFEQ-R18), which is a revised version of the 52-item Three-Factor Eating Questionnaire (TFEQ). The TFEQ-R18 includes eighteen total items that assess emotional eating, uncontrolled eating, and cognitive restraint. The current study assessed emotional eating specifically. Emotional eating items (3 items) included statements such as, "When I feel 
anxious, I find myself eating". Responses are provided with a 4-point Likert scale from 1 (definitely true) to 4 (definitely false). Higher scores indicate greater emotional eating. This questionnaire has demonstrated good factor structure and construct validity among adolescents [53]. Prior studies suggest that this measure has internal consistency, with acceptable Cronbach's alpha coefficients ranging from 0.77 to 0.84 [54]. The current study also demonstrated internal consistency, with a Cronbach's alpha coefficient of 0.81 .

\subsubsection{Dietary Outcomes}

Adolescent dietary outcomes were collected using three random 24-h dietary recalls conducted with a registered dietician, which has been shown to be a valid measure [55]. It is the gold standard to conduct three 24-h dietary recalls to determine dietary intake in adolescents [56,57]. The telephone-administered recalls were completed on two weekdays and one weekend day. Adolescents were provided instructions at their FIT baseline visit on how to properly estimate portion sizes. During the recall, participants were asked to describe the type and amount of food they had eaten the day before. Daily F\&V (with fried F\&V items removed) and sweetened beverage intake (servings), energy intake (kilocalories), total fat and saturated fat intake (grams) were estimated, and each outcome was averaged from the completed recalls for the current study.

\subsubsection{Parental Feeding Practices}

The Child Feeding Questionnaire (CFQ) was used to measure adolescent-reported parental feeding practices. The phrasing of the items was revised to reflect adolescent's perspective of their parent's feeding practices, as this measure is typically completed by the parent. Prior studies have shown that this is a valid approach to assess adolescents perception of parental feeding practices [42]. This questionnaire included 21 items that assessed five subscales: perceived parental responsibility, parental concern about a child's weight, parental restriction, parental monitoring, and parental pressure-to-eat. Responses are captured with a 5-point Likert scale to determine the frequency of feeding practices ("never" to "always") and the degree of agreement with a statement ("disagree" to "agree"). The current study included the following subscales: perceived parental responsibility ( 3 items, i.e., "How often is your parent responsible for deciding if you have eaten the right kind of foods?"), parental concern about a child's weight (3 items, i.e., "How concerned is your parent about you dieting to maintain desirable weight?"), parental restriction (8 items, i.e., "Does your parent have to watch that you do not eat too much of your favorite foods?"), parental monitoring ( 3 items, i.e., "How often does your parent keep track of the sweets (candy, ice cream, cake, pies, and pastries) that you eat?"), and parental pressure-to-eat (4 items, i.e., "If you say, 'I'm not hungry', does your parent believe you should try to eat anyway?"). For each subscale, the scores were the sum of items included in the respective subscale. This measure has been shown to be a reliable scale across prior national studies [58]. The current study showed adequate reliability for this scale (monitoring, $\alpha=0.91$; responsibility, $\alpha=0.66$; restriction, $\alpha=0.88$; pressure-to-eat, $\alpha=0.65$; concern, $\alpha=0.88$ ).

\subsection{Statistical Analysis}

Analyses were conducted with IBM SPSS Statistics Version 26 and R-studio. The data were assessed for normality and outliers. Multicollinearity was examined to confirm that all VIF values were below 10 [59]. A hierarchical linear regression was utilized to examine the interaction between parental feeding practices (responsibility, monitoring, concern, restriction, and pressure-to-eat) and adolescent emotional eating predicting dietary outcomes (F\&Vs, energy intake, sweetened beverages, total fat, and saturated fat). Regression analyses for each dietary outcome were run with and without covariates. Unadjusted regression analyses were conducted and did not change the overall results for each dietary outcome. Adjusted regression analyses were also run to test the interactions separately for each dietary outcome, which did not result in significant changes to the overall results. For 
unadjusted analyses, the first step of the model included the main effects of the predictors and the second step added the interaction terms; for adjusted analyses, a third step of the model added covariates. The third step of the model allowed us to examine whether adjusting for covariates impacted the model. Adjusted models included the following covariates: adolescent sex, adolescent age, parent education, parent BMI, and group treatment. These covariates have shown to be associated with adolescent dietary outcomes [60]. An omnibus F-test was utilized to evaluate effects with all interaction terms considered together in one model. This is a conservative statistical approach that has been utilized in prior studies assessing simultaneous interaction effects to decrease the likelihood of a type 1 error rate [61]. Separate models were constructed for each continuous dietary outcome. Adolescent sex (e.g., male vs. female), parent education (e.g., college vs. no college), and group treatment (e.g., intervention vs. control group) were dummy-coded for analyses.

Dietary data were cleaned prior to conducting analyses. Consistent with previous studies [62], to account for extreme scores in kcals, energy intake was corrected such that the minimum was set to 500 and the maximum was set to 5000, which resulted in the recoding of less than $2 \%$ of daily observations. Additionally, to account for extreme scores in total fat, saturated fat, and sweetened beverages, a Winsorizing approach was applied [63]. Specifically, extreme scores were recoded to three times the interquartile range, which allowed for the inclusion of all data, while also reducing the effect of potential outliers. This approach led to the recoding of less than $6 \%$ of observations across the dietary outcomes.

Scores for emotional eating and parental feeding practices were calculated by norming each item before summation. Thus, summed scale scores were transformed to z-scores to aid in analysis and interpretation of statistical models. F\&V intake was indexed by summing the averages of daily F\&V intake. Analyses were conducted on participants with at least one dietary recall, as not all participants were able to complete three recalls. Simple slope analyses plotted at $1 \mathrm{SD}$ above and below the mean were conducted to decompose the significant interactive effects. The alpha level was set to $p<0.05$. Overall, 23 participants were removed from analyses due to incomplete emotional eating and/or dietary recall data, resulting in a total of 127 participants with complete data that were included in analyses.

\section{Results}

\subsection{Demographics and Anthropometrics}

Table 1 provides the demographic information for the study sample. Of the 127 participants included in the current study, the sample of adolescents was predominantly female $(65.4 \%)$, and the average age was 12.83 years old. The average BMI percentile for this sample of adolescents was 96.61, with similar rates of obesity among parents (BMI $37.46 \pm 8.022$ ). A total of $42.9 \%$ of parents had attended some college and the average household income ranged from $\$ 25 \mathrm{k}$ to $\$ 39 \mathrm{k}$. 
Table 1. Sample characteristics.

\begin{tabular}{|c|c|}
\hline & Total $(N=127)$ \\
\hline Age (years), $\mathrm{M} \pm \mathrm{SD}$ & $12.83 \pm 1.745$ \\
\hline \multicolumn{2}{|l|}{ Race, $\%$} \\
\hline African American & 100 \\
\hline Female, $\%$ & 65.4 \\
\hline BMI Percentile $\left(\mathrm{kg} / \mathrm{m}^{2} \%\right), \mathrm{M} \pm \mathrm{SD}$ & $96.61 \pm 4.142$ \\
\hline Daily Energy Intake (kcals), $\mathrm{M} \pm \mathrm{SD}$ & $1667.79 \pm 510.652$ \\
\hline Parent BMI $\left(\mathrm{kg} / \mathrm{m}^{2}\right), \mathrm{M} \pm \mathrm{SD}$ & $37.46 \pm 8.022$ \\
\hline \multicolumn{2}{|l|}{ Annual Household Income, \% } \\
\hline Less than $10 \mathrm{k}$ & 11.9 \\
\hline $10-24 k$ & 20.6 \\
\hline $25-39 k$ & 27.0 \\
\hline $40-54 \mathrm{k}$ & 13.5 \\
\hline $55-69 k$ & 8.7 \\
\hline $70-84 \mathrm{k}$ & 4.0 \\
\hline $85 \mathrm{k}+$ & 14.3 \\
\hline \multicolumn{2}{|l|}{ Parent Education, \% } \\
\hline 9-11 years & 3.2 \\
\hline 12 years & 12.7 \\
\hline Some college & 42.9 \\
\hline 4-year college & 17.5 \\
\hline Professional & 23.8 \\
\hline \multicolumn{2}{|l|}{ Marital Status, \% } \\
\hline Married & 35.7 \\
\hline Separated & 14.3 \\
\hline Divorced & 20.6 \\
\hline Widowed & 2.4 \\
\hline Never Married & 19.8 \\
\hline In an unmarried couple & 7.1 \\
\hline \multicolumn{2}{|l|}{ Number of Children at Home, $\%$} \\
\hline 0 & 5.6 \\
\hline $1-2$ & 63.5 \\
\hline $3-4$ & 28.5 \\
\hline $5-6$ & 1.6 \\
\hline 7 & 0.8 \\
\hline
\end{tabular}

Note: $\mathrm{M}$ = mean; $\mathrm{SD}$ = standard deviation; $\mathrm{BMI}=$ body mass index, Avg. = average; $\mathrm{k}$ = thousand.

\subsection{Correlational Analysis}

Correlation analyses indicated that adolescent emotional eating was significantly correlated with F\&V intake $(r=0.18)$. Furthermore, parent education was significantly associated with parent body mass index $(r=-0.19)$. A number of the parental feeding practices were significantly correlated with each other in the expected direction; these are modest correlations ranging from $r=0.16$ to 0.49 (Table 2). 
Table 2. Correlations among parental feeding practices, adolescent emotional eating, and adolescent dietary intake.

\begin{tabular}{|c|c|c|c|c|c|c|c|c|c|c|c|c|}
\hline & 1 & 2 & 3 & 4 & 5 & 6 & 7 & 8 & 9 & 10 & 11 & 12 \\
\hline 1. Adolescent Age & - & & & & & & & & & & & \\
\hline 2. Adolescent Sex & 0.05 & - & & & & & & & & & & \\
\hline 3. Treatment Group & -0.02 & $<0.01$ & - & & & & & & & & & \\
\hline 4. Parent BMI & -0.09 & 0.13 & 0.02 & - & & & & & & & & \\
\hline 5. Parent College & 0.09 & -0.16 & -0.14 & $-0.19 *$ & - & & & & & & & \\
\hline 6. Emotional Eating & -0.08 & -0.08 & 0.03 & 0.13 & 0.11 & - & & & & & & \\
\hline 7. Parental Responsibility & $-0.29 * *$ & 0.05 & -0.04 & -0.002 & 0.01 & 0.13 & - & & & & & \\
\hline 8. Parental Concern & -0.13 & -0.13 & -0.08 & -0.09 & 0.16 & 0.14 & $0.40 * *$ & - & & & & \\
\hline 9. Parental Monitoring & -0.11 & -0.06 & -0.07 & -0.11 & 0.15 & -0.07 & $0.49 * *$ & $0.47 * *$ & - & & & \\
\hline 10. Parental Restriction & $-0.33 * *$ & -0.09 & -0.01 & -0.02 & 0.01 & $0.18 *$ & $0.41 * *$ & $0.34^{* *}$ & $0.46^{* *}$ & - & & \\
\hline 11. Parental Pressure-to-Eat & -0.17 & -0.13 & 0.09 & $<0.01$ & -0.02 & 0.16 & $0.22 *$ & 0.16 & $0.33 * *$ & $0.41^{* *}$ & - & \\
\hline $\begin{array}{l}\text { 12. Adolescent Fruit and } \\
\text { Vegetable Intake }\end{array}$ & -0.06 & -0.05 & 0.05 & -0.01 & 0.07 & 0.18 * & 0.02 & -0.04 & 0.06 & 0.03 & 0.02 & - \\
\hline
\end{tabular}

Note: ${ }^{*}$ Indicates correlations significant with alpha criteria of $p<0.05$; ${ }^{* *}$ indicates correlations significant with alpha criteria of $p<0.01$. Column headings correspond to row names.

\subsection{Parental Feeding Practices and Emotional Eating on Fruit and Vegetable Intake}

The moderating effect of parental feeding practices and adolescent emotional eating on F\&V intake was assessed with unadjusted and adjusted hierarchical linear regression models (Table 3). Results of the adjusted model are presented. The first step of the regression model included only the main effects (parental feeding practices and emotional eating) and revealed an insignificant F change $(p=0.324)$. The second step of the model added all the interaction terms together in one model and yielded a significant $\mathrm{F}$ change $(p=0.001)$. The final step of the model added covariates and did not yield a significant $\mathrm{F}$ change from the second step of the model $(p=0.906)$, suggesting that the model did not change significantly with the addition of covariates. There was a significant main effect of emotional eating on $\mathrm{F} \& \mathrm{~V}$ intake $(B=0.397, S E=0.157, p=0.013)$, such that greater emotional eating was associated with greater $\mathrm{F} \& \mathrm{~V}$ intake. There was a significant interaction between parental feeding practices (monitoring of a child's eating) and emotional eating on $\mathrm{F} \& \mathrm{~V}$ intake $(B=0.524, S E=0.176, p=0.004)$. There was also a significant interaction between parental feeding practices (restriction, concern about a child's weight, $B=-0.331$, $S E=0.162, p=0.043 ; B=-0.602, S E=0.171, p=0.001$, respectively) and emotional eating on $\mathrm{F} \& \mathrm{~V}$ intake. Adjusted hierarchical linear regression analyses were also conducted with the inclusion of adolescent body mass index (zBMI) and removal of adolescent sex as covariates in the model. All original results for the final step of the adjusted model for F\&V intake remained statistically significant $(p<0.05)$, except for a small change in one of the interaction effects (restriction, $p=0.055$ ). Adolescent baseline zBMI was not a significant predictor in the adjusted model.

Simple slopes analyses indicated that for parents with high monitoring of a child's eating $(B=0.866, S E=0.253, p=0.001$, Figure $1 \mathrm{a})$, emotional eating was positively associated with $\mathrm{F} \& \mathrm{~V}$ intake. Further, among parents with low restriction of a child's eating $(B=0.672$, $S E=0.212, p=0.002$, Figure $1 b)$ or low concern about a child's weight $(B=0.933, S E=0.227$, $p=0.000$, Figure 1c), simple slopes analyses showed that emotional eating was positively associated with $F \& V$ intake. None of the other parenting factors interacted with emotional eating in predicting $F \& V$ intake. 
Table 3. Hierarchical regression analyses assessing the interaction effects of parental feeding practices and adolescent emotional eating on adolescent fruit and vegetable intake.

\begin{tabular}{|c|c|c|c|c|c|c|c|c|}
\hline & Model & $B$ & $S E$ & $t$ & $p$ & $R^{2}$ & $\Delta R^{2}$ & $\Delta \mathrm{F}$ Sig \\
\hline \multirow[t]{7}{*}{1} & Intercept & 2.419 & 0.140 & 17.268 & $0.000 *$ & 0.056 & 0.056 & 0.324 \\
\hline & Emotional Eating & 0.361 & 0.152 & 2.378 & 0.019 * & & & \\
\hline & Responsibility & -0.051 & 0.171 & -0.298 & 0.766 & & & \\
\hline & Concern & -0.212 & 0.168 & -1.262 & 0.209 & & & \\
\hline & Monitoring & 0.280 & 0.187 & 1.497 & 0.137 & & & \\
\hline & Restriction & -0.027 & 0.167 & -0.162 & 0.871 & & & \\
\hline & Pressure-to-Eat & -0.068 & 0.166 & -0.411 & 0.682 & & & \\
\hline \multirow[t]{12}{*}{2} & Intercept & 2.589 & 0.139 & 18.679 & $0.000 *$ & 0.206 & 0.150 & $0.001^{*}$ \\
\hline & Emotional Eating & 0.395 & 0.151 & 2.613 & $0.010 *$ & & & \\
\hline & Responsibility & -0.121 & 0.162 & -0.746 & 0.457 & & & \\
\hline & Concern & -0.204 & 0.161 & -1.261 & 0.210 & & & \\
\hline & Monitoring & 0.236 & 0.178 & 1.328 & 0.187 & & & \\
\hline & Restriction & 0.048 & 0.159 & 0.304 & 0.762 & & & \\
\hline & Pressure-to-Eat & -0.031 & 0.158 & -0.195 & 0.846 & & & \\
\hline & EE*Responsibility & 0.083 & 0.163 & 0.508 & 0.613 & & & \\
\hline & $\mathrm{EE}^{*}$ Concern & -0.575 & 0.164 & -3.507 & $0.001 *$ & & & \\
\hline & EE*Monitoring & 0.535 & 0.169 & 3.163 & $0.002 *$ & & & \\
\hline & EE*Restriction & -0.343 & 0.154 & -2.222 & $0.028 *$ & & & \\
\hline & EE*Pressure-to-Eat & 0.022 & 0.159 & 0.138 & 0.890 & & & \\
\hline \multirow[t]{17}{*}{3} & Intercept & 3.607 & 1.370 & 2.632 & $0.010^{*}$ & 0.218 & 0.011 & 0.906 \\
\hline & Emotional Eating & 0.397 & 0.157 & 2.525 & $0.013^{*}$ & & & \\
\hline & Responsibility & -0.119 & 0.171 & -0.695 & 0.489 & & & \\
\hline & Concern & -0.236 & 0.167 & -1.411 & 0.161 & & & \\
\hline & Monitoring & 0.256 & 0.186 & 1.376 & 0.172 & & & \\
\hline & Restriction & 0.009 & 0.169 & 0.052 & 0.959 & & & \\
\hline & Pressure-to-Eat & -0.046 & 0.165 & -0.278 & 0.781 & & & \\
\hline & EE*Responsibility & 0.113 & 0.171 & 0.659 & 0.511 & & & \\
\hline & $\mathrm{EE}^{*}$ Concern & -0.602 & 0.171 & -3.528 & $0.001 *$ & & & \\
\hline & EE*Monitoring & 0.524 & 0.176 & 2.981 & $0.004^{*}$ & & & \\
\hline & EE*Restriction & -0.331 & 0.162 & -2.047 & $0.043^{*}$ & & & \\
\hline & EE*Pressure-to-Eat & 0.034 & 0.165 & 0.206 & 0.837 & & & \\
\hline & Adolescent Age & -0.051 & 0.087 & -0.586 & 0.559 & & & \\
\hline & Adolescent Sex & -0.251 & 0.298 & -0.841 & 0.402 & & & \\
\hline & Treatment Group & 0.107 & 0.277 & 0.386 & 0.701 & & & \\
\hline & Parent BMI & -0.009 & 0.018 & -0.501 & 0.617 & & & \\
\hline & Parent College & -0.021 & 0.296 & -0.070 & 0.945 & & & \\
\hline
\end{tabular}

Note: * Indicates a significant alpha criteria of $p<0.05$. BMI = body mass index; EE = emotional eating. Models 1 and 2 include findings from the two steps of the unadjusted regression analyses; Model 3 includes the findings from the final step of the adjusted regression analyses. 


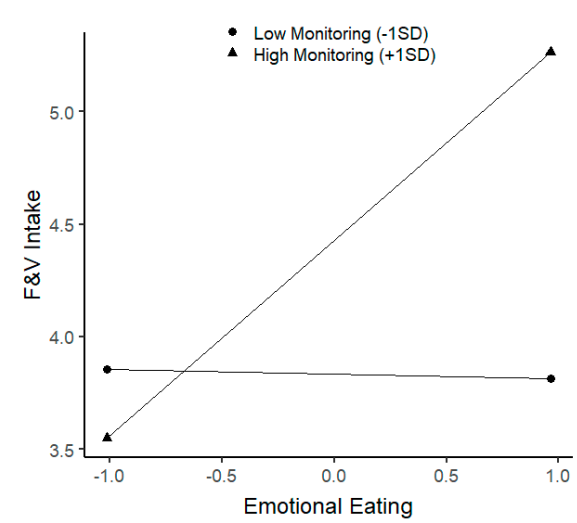

(a)

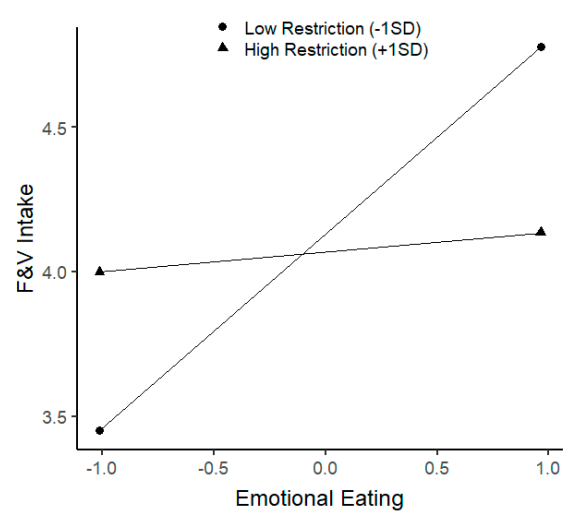

(b)

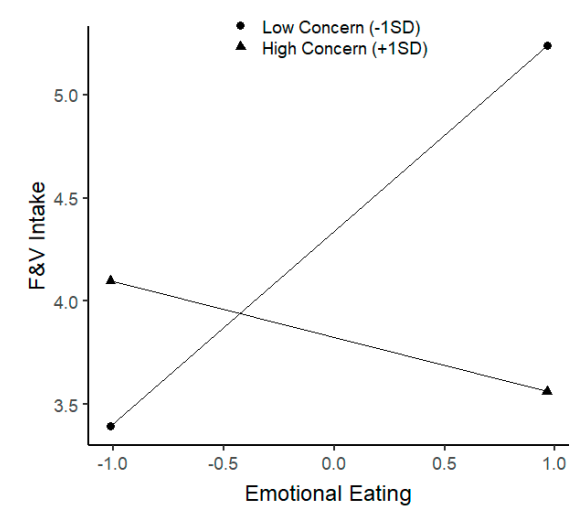

(c)

Figure 1. Significant interactions of parental feeding practices and emotional eating on fruit and vegetable intake. (a) The interaction between monitoring of a child's eating and emotional eating on fruit and vegetable intake. (b) The interaction between restriction of a child's eating and emotional eating on fruit and vegetable intake. (c) The interaction between concern about a child's weight and emotional eating on fruit and vegetable intake.

\subsection{Parental Feeding Practices and Adolescent Emotional Eating on Energy Intake (kcals)}

The first and second step of the regression model for energy intake yielded an insignificant $\mathrm{F}$ change ( $p=0.602, R^{2}=0.037 ; p=0.659, R^{2}=0.064$, respectively). The final step of the regression model for energy intake yielded a significant F-change $\left(p=0.024, R^{2}=0.168\right)$; there was a main effect of parent education on adolescent energy intake $(B=-297.480$, $S E=99.501, p=0.003$ ), such that higher parent college education was associated with lower energy intake. There were no significant main effects or interactions with the parenting factors or emotional eating in the final step of the model.

\subsection{Parental Feeding Practices and Adolescent Emotional Eating on Sweetened Beverage Intake}

The final step of the regression model yielded insignificant $F$ changes for sweetened beverage intake $(p=0.208)$.

\subsection{Parental Feeding Practices and Adolescent Emotional Eating on Total Fat Intake}

The final step of the regression model revealed insignificant $F$ changes for total fat intake $(p=0.146)$.

\subsection{Parental Feeding Practices and Adolescent Emotional Eating on Saturated Fat Intake}

The final step of the regression model indicated insignificant $\mathrm{F}$ changes for saturated fat intake $(p=0.270)$.

\subsection{Power Analyses}

Power analyses were conducted using the R package "retrodesign" to determine the size of the interaction we had power to detect for the results presented in Table 3 [64]. For the five interactions, we had $\geq 80 \%$ power to find detectable differences between servings of $F \& V$ in the range of $0.62-1.94$. Previous systematic reviews on changes in F\&V suggest that an effect of 1 serving or greater is a large effect size $[65,66]$. Thus, in this study, we had power to detect a medium to large effect size for the interactions studied.

\section{Discussion}

The purpose of the current study was to evaluate the interaction between parental feeding practices and adolescent emotional eating on dietary outcomes among overweight African American adolescents. The results demonstrated that, with greater parental monitoring, emotional eating was positively associated with higher F\&V intake. Further, for lower parental restriction and parental concern about a child's weight, emotional eating was positively associated with F\&V intake. No other findings were significant. Overall, 
these results demonstrated that higher levels of parental monitoring, as well as lower restriction and concern about a child's weight, buffered the effect of emotional eating on poor-dietary-quality outcomes, as only F\&V intake was associated with emotional eating. These results are consistent with our hypotheses that greater monitoring and less restrictive parental feeding practices may buffer the relationship between adolescent emotional eating and low F\&V dietary intake in overweight African American adolescents.

In the current study, we found that, under high parental monitoring of the adolescent's eating, adolescent emotional eating was positively associated with F\&V intake. This finding of monitoring as a buffer of problematic adolescent eating habits aligns with prior research that shows that, under low (or average), but not high, levels of parental monitoring, a positive association between impulsivity and emotional eating has been demonstrated among predominantly White preadolescents [42]. Thus, reduced parental monitoring was related to greater emotional eating among youth who are at risk for impulsivity. Together, the current study and past studies [42] suggest that high parental monitoring may be a protective moderating factor for adolescent eating and diet-related outcomes (emotional eating and F\&V intake). The current study, however, extends these findings to a highrisk group of overweight African American adolescents and examines the link between emotional eating and dietary quality ( $F \& V$ intake). Considering that African American families face disproportionate social environmental chronic stressors that may place their families at greater risk for emotional eating compared to their White peers [15-18], these findings are particularly important and may inform future interventions.

The current study also found that, with lower levels of parental restriction of a child's eating, adolescent emotional eating was positively associated with greater F\&V intake. These findings suggest that reduced parental restriction may serve as a buffer of low F\&V dietary intake in overweight African American adolescents. A previous study found that, under greater levels of parental restriction, reward sensitivity (i.e., response to reward cues) was positively associated with high-fat, high-sugar snack food intake (cookies, pastries, fries, etc.) among Flemish adolescents [37]. The current study is consistent with these past findings, as it indicates that less parental restriction may moderate adolescent emotional eating in improving dietary intake of F\&Vs among overweight African American adolescents. While some prior research has shown that restrictive feeding practices are related to greater F\&V intake within low-income samples of predominantly African American adolescents [31], the current findings and some prior studies with low-income minority children (38\% African American) indicate that less restrictive feeding practices may be protective [34]. Notably, another study including a low-income sample of predominantly African American preadolescents (92\% African American) found that parents with greater authoritarian and authoritative parenting predicted the highest adolescent dietary quality [67]. The authors proposed that parents may be utilizing helpful parenting practices from both approaches. It is plausible that some African American parents utilizing modest restrictive parental feeding practices are also demonstrating support and warmth through other parenting practices (authoritative parenting), resulting in better dietary quality among youth. This study and other investigators suggest that parenting practices among African American families may be better understood with the utilization of culturally appropriate measures and further examination of within-group differences [33]. Thus, additional research with African American adolescents is needed to identify the role of relevant contextual factors, individual differences, or other parent-adolescent dynamics on adolescent dietary quality.

Our results also indicated that, under low parental concern about a child's weight, emotional eating was positively associated with F\&V intake. Thus, decreased levels of parental concern may be protective of poor F\&V dietary intake among African American adolescents. Few studies have examined parental concern about a child's weight as a moderating factor of adolescent eating behaviors or diet; however, this parental feeding practice has been related to elevated adolescent stress-eating [68], weight status [69], and greater utilization of other restrictive parental feeding practices [70]. Further research is 
needed to elucidate the moderating effects of parental concern about a child's weight on adolescent emotional eating and dietary intake and to examine the possible associations with weight stigma [71].

Of note, the results of this study showed a main effect of parent college education on adolescent energy intake, such that greater parent college education predicted healthier energy intake (reductions in kcals). This finding is important and aligns with prior research indicating that higher parental education levels are associated with lower intake of energy-dense foods among children and adolescents [72,73]. On average, the adolescents' caregivers in our sample reported an educational status lower than a 4-year degree $(58 \%)$, which may be important for understanding energy intake among our adolescent participants. Further studies should consider the relationship between parental education and parental feeding practices on adolescent dietary intake.

Our results indicated that the unadjusted models for energy intake, sweetened beverage intake, total fat intake, and saturated fat intake did not yield significant effects; however, the adjusted final model for energy intake did yield a significant main effect. Although sweetened beverage, energy, total fat, and saturated fat intake have been linked to parental feeding practices [74-76], limited studies have assessed emotional eating in relation to these dietary outcomes. In addition, there is growing research demonstrating that more than three dietary recalls are needed to show valid dietary assessments among adolescents [77]. However, emotional eating has been more closely linked to F\&V intake, with some studies showing greater intake and others indicating lower intake of F\&Vs $[7,8]$. More studies are needed to elucidate which dietary outcomes are related to adolescent emotional eating and further delineate how parenting factors may moderate emotional eating on understanding dietary outcomes. There may be individual differences in the type and amount of food that adolescents consume when eating in response to negative emotions. While some adolescents increase consumption of specific foods while engaging in emotional eating, others increase their overall intake of a variety of foods [7]. Thus, within our sample, the moderating effect of parental feeding practices may be more useful in examining emotional eating related to specific foods, such as F\&V, rather than the overall amount or the nutritional makeup of food intake. It is also plausible that adolescents may be more willing to add more F\&Vs to their diet than remove high-fat, high-sugar foods, but it will be important for longitudinal data to expand on the current research. Additional research on the family eating behaviors, such as family mealtime or parental emotional eating, may also inform the relationship between adolescent emotional eating and dietary intake.

This study has several limitations. First, it is a cross-sectional study, and causal inferences cannot be made, and we cannot confirm the direction of our effects. Longitudinal analyses are needed to better understand the influence of the home climate on adolescent emotional eating and dietary intake over time. Specifically, longitudinal data would provide insights into whether parental feeding practices elicit changes in emotional eating and dietary intake or if these problematic eating behaviors evoke certain parental feeding practices. Further, evaluating the development of emotional eating within the context of the home environment from childhood into adolescence will be informative, such as assessing how parents may model emotional eating. Moreover, understanding and intervening on emotional eating early in development through a family systems lens is critical to offset poor health trajectories into young adulthood. This study is also limited in that only three dietary recalls were administered which may result in unreliable dietary data [77] and thus may explain why only F\&V intake was found to show significant interactions in the present study. Further, another limitation of this study may be that the current sample underreported their overall energy intake, given that our sample's average energy intake is lower than typically reported in national studies with overweight adolescent samples [78]. Though it is the gold standard that diet-related studies collect three dietary recalls, research indicates that between 8 and 32 recalls are recommended for adequate reliability [77]. Further, our findings are limited given that the sample included overweight 
or obese African American adolescents from an urban area in the Southeast US, which may limit generalizability to normal-weight adolescents and non-minorities or families living outside the Southeast.

In summary, the findings in the current study suggest that, under high parental monitoring, as well as low restriction and concern about a child's weight, emotional eating is related to greater $F \& V$ intake. Thus, parental feeding practices such as monitoring, as well as lower levels of restrictive practices, may be related to F\&V dietary outcomes among African American adolescents. These findings are particularly noteworthy, considering the mixed literature regarding monitoring feeding practices versus restrictive feeding practices and adolescent eating behaviors within African American families [31,34]. Additional data are needed to further elucidate potential cultural differences in these parenting practices, including the influence of social environmental conditions and risk factors that are salient to African American families. Moreover, future studies are needed to better address how parenting factors or other relevant constructs may attenuate adolescent emotional eating and promote more adaptive coping strategies, such as eating higher-dietary-quality options (e.g., F\&Vs). Given the notable influence of parental feeding practices on adolescent eating behaviors shown in our findings, it will also be important for future interventions to integrate a family systems approach.

Author Contributions: Conceptualization, M.Q., D.K.W. and A.M.S.; methodology, M.Q., D.K.W. and A.M.S.; software, M.Q. and A.M.S.; validation, N/A; formal analysis, M.Q. and A.M.S.; investigation, D.K.W.; resources, D.K.W.; data curation, A.M.S., D.K.W. and M.Q.; writing-original draft preparation, M.Q. and D.K.W.; writing—review and editing, M.Q., D.K.W., A.M.S. and N.Z.; visualization, N/A; supervision, D.K.W.; project administration, D.K.W.; funding acquisition, M.Q. and D.K.W. All authors have read and agreed to the published version of the manuscript.

Funding: This research was funded by a grant (R01 HD072153) funded by the National Institutes of Child Health and Human Development to Dawn K. Wilson, Ph.D., Trial registration: ClinicalTrials.gov NCT01796067. Registered 23 January 2013; and by a General Medical Science grant (T32 GM08740) to Mary Quattlebaum.

Institutional Review Board Statement: This study was conducted according to the guidelines of the Declaration of Helsinki, and approved by the Institutional Review Board of the University of South Carolina (Protocol Code: Pro00016136, approved on 23 January 2013).

Informed Consent Statement: Informed consent and assent were obtained from all subjects involved in the study.

Data Availability Statement: The data presented in this study are available upon request from the corresponding author. The data are not currently publicly available, as the outcome paper has not yet been published.

Conflicts of Interest: The authors declare no conflict of interest.

\section{References}

1. Hales, C.M.; Carroll, M.D.; Fryar, C.D.; Ogden, C.L. Prevalence of Obesity among Adults and Youth: United States, 2015-2016. NCHS Data Brief 2017, 288, 1-8.

2. Ogden, C.L.; Carroll, M.D.; Kit, B.K.; Flegal, K.M. Prevalence of Childhood and Adult Obesity in the United States, $2011-2012$. JAMA 2014, 311, 806-814. [CrossRef] [PubMed]

3. Lee, E.Y.; Yoon, K.-H. Epidemic obesity in children and adolescents: Risk factors and prevention. Front. Med. 2018, 12, 658-666. [CrossRef]

4. Lowe, M.R.; Fisher, E.B. Emotional reactivity, emotional eating, and obesity: A naturalistic study. J. Behav. Med. 1983, 6, 135-149. [CrossRef]

5. Lopez-Cepero, A.; Frisard, C.F.; Lemon, S.C.; Rosal, M.C. Association between emotional eating, energy-dense foods and overeating in Latinos. Eat. Behav. 2019, 33, 40-43. [CrossRef] [PubMed]

6. Sims, R.; Gordon, S.; Garcia, W.; Clark, E.; Monye, D.; Callender, C.; Campbell, A. Perceived stress and eating behaviors in a community-based sample of African Americans. Eat. Behav. 2008, 9, 137-142. [CrossRef] [PubMed]

7. Nguyen-Michel, S.T.; Unger, J.B.; Spruijt-Metz, D. Dietary correlates of emotional eating in adolescence. Appetite 2007, 49, 494-499. [CrossRef] 
8. Cartwright, M.; Wardle, J.; Steggles, N.; Simon, A.E.; Croker, H.; Jarvis, M. Stress and dietary practices in adolescents. Health Psychol. 2003, 22, 362-369. [CrossRef]

9. Steinegger, C.; Dorn, L.; Goody, C.; Khoury, P.R.; Daniels, S.R. Emotional eating in adolescent females. J. Adolesc. Health 2005, 36, 152. [CrossRef]

10. Rose, L.M.H.; Nadler, E.P.; Mackey, E.R. Impulse Control in Negative Mood States, Emotional Eating, and Food Addiction are Associated with Lower Quality of Life in Adolescents with Severe Obesity. J. Pediatr. Psychol. 2017, 43, 443-451. [CrossRef] [PubMed]

11. Munkholm, A.; Olsen, E.M.; Rask, C.U.; Clemmensen, L.; Rimvall, M.K.; Jeppesen, P.; Micali, N.; Skovgaard, A.M. Eating behaviours in preadolescence are associated with body dissatisfaction and mental disorders-Results of the CCC2000 study. Appetite 2016, 101, 46-54. [CrossRef] [PubMed]

12. van Strien, T.; Beijers, R.; Smeekens, S.; Winkens, L.H.; Konttinen, H. Parenting quality in infancy and emotional eating in adolescence: Mediation through emotion suppression and alexithymia. Appetite 2019, 141, 104339. [CrossRef]

13. Birch, L.L.; Fisher, J.O. Development of eating behaviors among children and adolescents. Pediatrics 1998, 101, 539-549. [PubMed]

14. Hager, E.R.; Cockerham, A.; O’Reilly, N.; Harrington, D.; Harding, J.; Hurley, K.M.; Black, M.M. Food swamps and food deserts in Baltimore City, MD, USA: Associations with dietary behaviours among urban adolescent girls. Public Health Nutr. 2017, 20, 2598-2607. [CrossRef] [PubMed]

15. McLoyd, V.C. The Impact of Economic Hardship on Black Families and Children: Psychological Distress, Parenting, and Socioemotional Development. Child Dev. 1990, 61, 311-346. [CrossRef] [PubMed]

16. Turner, R.J.; Avison, W.R. Status Variations in Stress Exposure: Implications for the Interpretation of Research on Race, Socioeconomic Status, and Gender. J. Health Soc. Behav. 2003, 44, 488-505. [CrossRef]

17. Copeland-Linder, N.; Lambert, S.F.; Chen, Y.-F.; Ialongo, N.S. Contextual Stress and Health Risk Behaviors among African American Adolescents. J. Youth Adolesc. 2010, 40, 158-173. [CrossRef]

18. Hoggard, L.S.; Volpe, V.; Thomas, A.; Wallace, E.; Ellis, K. The role of emotional eating in the links between racial discrimination and physical and mental health. J. Behav. Med. 2019, 42, 1091-1103. [CrossRef]

19. Larson, N.I.; Story, M.T.; Nelson, M.C. Neighborhood Environments: Disparities in Access to Healthy Foods in the U.S. Am. J. Prev. Med. 2009, 36, 74-81.e10. [CrossRef] [PubMed]

20. Parks, E.P.; Kazak, A.; Kumanyika, S.; Lewis, L.; Barg, F.K. Perspectives on Stress, Parenting, and Children's Obesity-Related Behaviors in Black Families. Health Educ. Behav. 2016, 43, 632-640. [CrossRef] [PubMed]

21. Broderick, C.B. Understanding Family Process: Basics of Family Systems Theory; SAGE Publications: Thousand Oaks, CA, USA, 1993.

22. Kitzman-Ulrich, H.; Wilson, D.K.; George, S.M.S.; Lawman, H.; Segal, M.; Fairchild, A. The Integration of a Family Systems Approach for Understanding Youth Obesity, Physical Activity, and Dietary Programs. Clin. Child Fam. Psychol. Rev. 2010, 13, 231-253. [CrossRef]

23. Maccoby, E.E.; Martin, J. Socialization in the context of the family: Parent-child interaction. In Handbook of Child Psychology: Volume 4. \{Socialization\}, Personality, and Social Development; Wiley: New York, NY, USA, 1983.

24. Lytle, L.A.; Varnell, S.; Murray, D.M.; Story, M.; Perry, C.; Birnbaum, A.S.; Kubik, M.Y. Predicting adolescents' intake of fruits and vegetables. J. Nutr. Educ. Behav. 2003, 35, 170-178. [CrossRef]

25. Alsharairi, N.A.; Somerset, S.M. Associations between Parenting Styles and Children's Fruit and Vegetable Intake. Ecol. Food Nutr. 2014, 54, 93-113. [CrossRef] [PubMed]

26. Fleary, S.A.; Ettienne, R. The relationship between food parenting practices, parental diet and their adolescents' diet. Appetite 2019, 135, 79-85. [CrossRef] [PubMed]

27. Langer, S.L.; Seburg, E.; JaKa, M.M.; Sherwood, N.E.; Levy, R.L. Predicting dietary intake among children classified as overweight or at risk for overweight: Independent and interactive effects of parenting practices and styles. Appetite 2017, 110, 72-79. [CrossRef]

28. Kröller, K.; Jahnke, D.; Warschburger, P. Are maternal weight, eating and feeding practices associated with emotional eating in childhood? Appetite 2013, 65, 25-30. [CrossRef]

29. LeCroy, M.N.; Siega-Riz, A.M.; Albrecht, S.S.; Ward, D.S.; Cai, J.; Perreira, K.M.; Isasi, C.R.; Mossavar-Rahmani, Y.; Gallo, L.C.; Castañeda, S.F.; et al. Association of food parenting practice patterns with obesogenic dietary intake in Hispanic/Latino youth: Results from the Hispanic Community Children's Health Study/Study of Latino Youth (SOL Youth). Appetite 2019, 140, $277-287$. [CrossRef] [PubMed]

30. Wilson, D.K.; Sweeney, A.M.; Kitzman-Ulrich, H.; Gause, H.; George, S.M.S. Promoting Social Nurturance and Positive Social Environments to Reduce Obesity in High-Risk Youth. Clin. Child Fam. Psychol. Rev. 2017, 20, 64-77. [CrossRef]

31. Hoerr, S.L.; Hughes, S.O.; Fisher, J.O.; Nicklas, T.A.; Liu, Y.; Shewchuk, R.M. Associations among parental feeding styles and children's food intake in families with limited incomes. Int. J. Behav. Nutr. Phys. Act. 2009, 6, 55. [CrossRef]

32. Lecuyer, E.A.; Swanson, D.P.; Cole, R.; Kitzman, H. Effect of African- and European-American maternal attitudes and limit-setting strategies on children's self-regulation. Res. Nurs. Health 2011, 34, 468-482. [CrossRef]

33. Tamis-LeMonda, C.S.; Briggs, R.D.; McClowry, S.G.; Snow, D.L. Challenges to the Study of African American Parenting: Conceptualization, Sampling, Research Approaches, Measurement, and Design. Parenting 2008, 8, 319-358. [CrossRef] 
34. Arlinghaus, K.R.; Vollrath, K.; Hernandez, D.C.; Momin, S.R.; O'Connor, T.M.; Power, T.G.; Hughes, S.O. Authoritative parent feeding style is associated with better child dietary quality at dinner among low-income minority families. Am. J. Clin. Nutr. 2018, 108, 730-736. [CrossRef] [PubMed]

35. Loncar, H.; Wilson, D.K.; Sweeney, A.M.; Quattlebaum, M.; Zarrett, N. Associations of parenting factors and weight related outcomes in African American adolescents with overweight and obesity. J. Behav. Med. 2021. [CrossRef]

36. Kipp, C.; Wilson, D.K.; Sweeney, A.M.; Zarrett, N.; Van Horn, M.L. Effects of Parenting and Perceived Stress on BMI in African American Adolescents. J. Pediatr. Psychol. 2021. [CrossRef] [PubMed]

37. Van Lippevelde, W.; Vervoort, L.; Vangeel, J.; Goossens, L. Can Parenting Practices Moderate the Relationship between Reward Sensitivity and Adolescents' Consumption of Snacks and Sugar-Sweetened Beverages? Nutrients 2020, 12, 178. [CrossRef]

38. Franken, I.H.; Muris, P. Individual differences in reward sensitivity are related to food craving and relative body weight in healthy women. Appetite 2005, 45, 198-201. [CrossRef]

39. De Cock, N.; Van Lippevelde, W.; Vervoort, L.; Vangeel, J.; Maes, L.; Eggermont, S.; Braet, C.; Lachat, C.; Huybregts, L.; Goossens, L.; et al. Sensitivity to reward is associated with snack and sugar-sweetened beverage consumption in adolescents. Eur. J. Nutr. 2015, 55, 1623-1632. [CrossRef] [PubMed]

40. Verbeken, S.; Braet, C.; Lammertyn, J.; Goossens, L.; Moens, E. How is reward sensitivity related to bodyweight in children? Appetite 2012, 58, 478-483. [CrossRef]

41. Davis, C.; Patte, K.; Levitan, R.; Reid, C.; Tweed, S.; Curtis, C. From motivation to behaviour: A model of reward sensitivity, overeating, and food preferences in the risk profile for obesity. Appetite 2007, 48, 12-19. [CrossRef]

42. Farrow, C.V. Do parental feeding practices moderate the relationships between impulsivity and eating in children? Eat. Behav. 2012, 13, 150-153. [CrossRef] [PubMed]

43. Tanofsky-Kraff, M.; McDuffie, J.R.; Yanovski, S.Z.; Kozlosky, M.; Schvey, N.A.; Shomaker, L.B.; Salaita, C.; Yanovski, J.A. Laboratory assessment of the food intake of children and adolescents with loss of control eating. Am. J. Clin. Nutr. 2009, 89, 738-745. [CrossRef]

44. Shank, L.M.; Crosby, R.D.; Grammer, A.C.; Shomaker, L.B.; Vannucci, A.; Burke, N.; Stojek, M.; Brady, S.M.; Kozlosky, M.; Reynolds, J.C.; et al. Examination of the Interpersonal Model of Loss of Control Eating in the Laboratory. Compr. Psychiatry 2017, 76, 36-44. [CrossRef]

45. Goossens, L.; Braet, C.; Van Vlierberghe, L.; Mels, S. Loss of control over eating in overweight youngsters: The role of anxiety, depression and emotional eating. Eur. Eat. Disord. Rev. 2009, 17, 68-78. [CrossRef]

46. Goossens, L.; Braet, C.; Decaluwé, V. Loss of control over eating in obese youngsters. Behav. Res. Ther. 2007, 45, 1-9. [CrossRef]

47. Hilbert, A.; Tuschen-Caffier, B.; Czaja, J. Eating behavior and familial interactions of children with loss of control eating: A laboratory test meal study. Am. J. Clin. Nutr. 2010, 91, 510-518. [CrossRef]

48. Schmidt, R.; Hiemisch, A.; Kiess, W.; Hilbert, A. Interaction Effects of Child Weight Status and Parental Feeding Practices on Children's Eating Disorder Symptomatology. Nutrients 2019, 11, 2433. [CrossRef]

49. Wilson, D.K.; Kitzman-Ulrich, H.; Resnicow, K.; Van Horn, M.L.; George, S.M.S.; Siceloff, E.R.; Alia, K.A.; McDaniel, T.; Heatley, V.; Huffman, L.; et al. An overview of the Families Improving Together (FIT) for weight loss randomized controlled trial in African American families. Contemp. Clin. Trials 2015, 42, 145-157. [CrossRef] [PubMed]

50. Alia, K.A.; Wilson, D.K.; McDaniel, T.; George, S.M.S.; Kitzman-Ulrich, H.; Smith, K.; Heatley, V.; Wise, C. Development of an innovative process evaluation approach for the Families Improving Together (FIT) for weight loss trial in African American adolescents. Eval. Program Plan. 2015, 49, 106-116. [CrossRef] [PubMed]

51. Coulon, S.M.; Wilson, D.K.; Van Horn, M.L.; Hand, G.A.; Kresovich, S. The Association of Neighborhood Gene-Environment Susceptibility with Cortisol and Blood Pressure in African-American Adults. Ann. Behav. Med. 2016, 50, 98-107. [CrossRef]

52. Huffman, L.E.; Wilson, D.K.; Kitzman-Ulrich, H.; Lyerly, J.E.; Gause, H.M.; Resnicow, K. Associations between Culturally Relevant Recruitment Strategies and Participant Interest, Enrollment and Generalizability in a Weight-loss Intervention for African American Families. Ethn. Dis. 2016, 26, 295-304. [CrossRef] [PubMed]

53. Anglé, S.; Engblom, J.; Eriksson, T.; Kautiainen, S.; Saha, M.-T.; Lindfors, P.; Lehtinen, M.; Rimpelä, A. Three factor eating questionnaire-R18 as a measure of cognitive restraint, uncontrolled eating and emotional eating in a sample of young Finnish females. Int. J. Behav. Nutr. Phys. Act. 2009, 6, 41. [CrossRef]

54. Karlsson, J.; Persson, L.-O.; Sjöström, L.; Sullivan, M. Psychometric properties and factor structure of the Three-Factor Eating Questionnaire (TFEQ) in obese men and women. Results from the Swedish Obese Subjects (SOS) study. Int. J. Obes. 2000, 24, 1715-1725. [CrossRef]

55. Thompson, F.E.; Subar, A.F. Dietary assessment methodology. In Nutrition in the Prevention and Treatment of Disease; Academic Press: Cambridge, MA, USA, 2017.

56. Patrick, K.; Calfas, K.J.; Norman, G.J.; Zabinski, M.F.; Sallis, J.F.; Rupp, J.; Covin, J.; Cella, J. Randomized Controlled Trial of a Primary Care and Home-Based Intervention for Physical Activity and Nutrition Behaviors. Arch. Pediatr. Adolesc. Med. 2006, 160, 128-136. [CrossRef]

57. Ebbeling, C.B.; Feldman, H.A.; Chomitz, V.R.; Antonelli, T.A.; Gortmaker, S.L.; Osganian, S.K.; Ludwig, D.S. A Randomized Trial of Sugar-Sweetened Beverages and Adolescent Body Weight. N. Engl. J. Med. 2012, 367, 1407-1416. [CrossRef] [PubMed]

58. Kaur, H.; Li, C.; Nazir, N.; Choi, W.S.; Resnicow, K.; Birch, L.L.; Ahluwalia, J.S. Confirmatory factor analysis of the child-feeding questionnaire among parents of adolescents. Appetite 2006, 47, 36-45. [CrossRef] [PubMed] 
59. Myers, R.H. Classical and Modern Regression with Applications, 2nd ed.; Duxbury/Thompson Learning: Belmont, CA, USA, 1990.

60. Wardle, J.; Guthrie, C.; Sanderson, S.; Birch, L.; Plomin, R. Food and activity preferences in children of lean and obese parents. Int. J. Obes. 2001, 25, 971-977. [CrossRef] [PubMed]

61. Aiken, L.S.; West, S.G.; Pitts, S.C.; Baraldi, A.N.; Wurpts, I.C. Multiple linear regression. In Handbook of Psychology, 2nd ed.; John Wiley \& Sons: New York, NY, USA, 2012. [CrossRef]

62. Frankenfeld, C.L.; Poudrier, J.K.; Waters, N.M.; Gillevet, P.M.; Xu, Y. Dietary Intake Measured from a Self-Administered, Online 24-Hour Recall System Compared with 4-Day Diet Records in an Adult US Population. J. Acad. Nutr. Diet. 2012, 112, 1642-1647. [CrossRef] [PubMed]

63. Dixon, W.J. Simplified Estimation from Censored Normal Samples. Ann. Math. Stat. 1960, 31, 385-391. [CrossRef]

64. Gelman, A.; Carlin, J.B. Beyond Power Calculations: Assessing Type S (Sign) and Type M (Magnitude) Errors. Perspect. Psychol. Sci. 2014, 9, 641-651. [CrossRef]

65. Delgado-Noguera, M.; Tort, S.; Martínez-Zapata, M.J.; Bonfill, X. Primary school interventions to promote fruit and vegetable consumption: A systematic review and meta-analysis. Prev. Med. 2011, 53, 3-9. [CrossRef]

66. Knai, C.; Pomerleau, J.; Lock, K.; McKee, M. Getting children to eat more fruit and vegetables: A systematic review. Prev. Med. 2006, 42, 85-95. [CrossRef] [PubMed]

67. Burke, M.P.; Jones, S.J.; Frongillo, E.A.; Blake, C.E.; Fram, M.S. Parenting styles are associated with overall child dietary quality within low-income and food-insecure households. Public Health Nutr. 2019, 22, 2835-2843. [CrossRef] [PubMed]

68. Smith, A.D.; Sanchez, N.; Reynolds, C.; Casamassima, M.; Verros, M.; Annameier, S.K.; Melby, C.; Johnson, S.A.; Lucas-Thompson, R.G.; Shomaker, L.B. Associations of parental feeding practices and food reward responsiveness with adolescent stress-eating. Appetite 2020, 152, 104715. [CrossRef]

69. Spruijt-Metz, D.; Lindquist, C.H.; Birch, L.L.; Fisher, J.O.; Goran, M.I. Relation between mothers' child-feeding practices and children's adiposity. Am. J. Clin. Nutr. 2002, 75, 581-586. [CrossRef]

70. Polfuss, M.L.; Frenn, M. Parenting and Feeding Behaviors Associated with School-Aged African American and White Children. West. J. Nurs. Res. 2011, 34, 677-696. [CrossRef] [PubMed]

71. Gold, J.M.; Weg, M.W.V. Investigating the relationship between parental weight stigma and feeding practices. Appetite 2020, 149, 104635. [CrossRef]

72. Scaglioni, S.; De Cosmi, V.; Ciappolino, V.; Parazzini, F.; Brambilla, P.; Agostoni, C. Factors Influencing Children's Eating Behaviours. Nutrients 2018, 10, 706. [CrossRef]

73. Desbouys, L.; Méjean, C.; De Henauw, S.; Castetbon, K. Socio-economic and cultural disparities in diet among adolescents and young adults: A systematic review. Public Health Nutr. 2020, 23, 843-860. [CrossRef]

74. Blaine, R.E.; Kachurak, A.; Davison, K.K.; Klabunde, R.; Fisher, J.O. Food parenting and child snacking: A systematic review. Int. J. Behav. Nutr. Phys. Act. 2017, 14, 146. [CrossRef]

75. Hendrie, G.; Sohonpal, G.; Lange, K.; Golley, R. Change in the family food environment is associated with positive dietary change in children. Int. J. Behav. Nutr. Phys. Act. 2013, 10, 4. [CrossRef]

76. Lee, Y.; Birch, L.L. Diet quality, nutrient intake, weight status, and feeding environments of girls meeting or exceeding the American Academy of Pediatrics recommendations for total dietary fat. Minerva Pediatr. 2002, 54, 179-186. [CrossRef] [PubMed]

77. George, S.M.S.; Van Horn, M.L.; Lawman, H.G.; Wilson, D.K. Reliability of 24-Hour Dietary Recalls as a Measure of Diet in African-American Youth. J. Acad. Nutr. Diet. 2016, 116, 1551-1559. [CrossRef] [PubMed]

78. Skinner, A.C.; Steiner, M.J.; Perrin, E.M. Self-Reported Energy Intake by Age in Overweight and Healthy-Weight Children in NHANES, 2001-2008. Pediatrics 2012, 130, e936-e942. [CrossRef] [PubMed] 